\title{
Dissection and Choice in the Science Classroom: Student Experiences, Teacher Responses, and a Critical Analysis of the Right to Refuse
}

\author{
Jan Oakley \\ Lakehead University
}

\begin{abstract}
Choice in dissection has been characterized as an issue that intersects with teacher freedoms and student rights, sometimes resulting in a struggle between the two. This study investigated the experiences of former students $(n=311)$ and teachers $(n=153)$ in Ontario, Canada to determine (a) whether students are being offered a choice between participating in a dissection and using an alternative, and (b) the impressions students and teachers hold toward choice-in-dissection policies. Surveys and interviews with both groups revealed that teachers do not always offer choice. Further, while the majority of the student sample reported that they were in favour of choice policies, less than half of the teachers supported their implementation. A consideration of these findings from a critical pedagogy standpoint highlights power dynamics and a privileging of traditional dissection in the classroom. It is argued that choice policies are progressive and necessary to de-centre the perception that dissection is the "best" way students can learn.
\end{abstract}

Classroom-based animal dissection has come under considerable criticism in the past decades. With an estimated 10-12 million animals killed per year for dissections in North America schools (Rosenberger, 1998), dissection raises deep questions about the ethics of harmful animal use in educational contexts. As a result, some have called for it to be discontinued at the Kindergarten-Grade 12 classroom level and replaced with alternative ways of learning (Balcombe, 2000; CCAC, 2010; Jukes \& Chiuia, 2003; Marr, 2001; Nobis, 2002).

The controversies associated with dissection, and the fact that some students do not want to dissect for personal, ethical, cultural, religious, or environmental reasons, suggest that granting students choice in dissection is an important pedagogical practice. And, at first glance, it would appear that a pedagogy of choice is gaining popularity. One important indicator comes from the development of student choice policies that give students the right to opt out of dissection and use an alternative instead. These policies are currently in place in five Canadian school boards (Vancouver School Board, Burnaby School District \#41, Central Okanagan School District \#23, Toronto District School Board, and South Shore District School Board) and legislated in 10 American states (Florida, 
California, Pennsylvania, New York, Rhode Island, Illinois, Virginia, Oregon, New Jersey, and Vermont), while school districts in six other American states have passed resolutions that encourage teachers to provide alternatives to dissection (in Louisiana, Massachusetts, New Mexico, Maine, Maryland, and Nevada) (AAVS, 2011; Duncan, 2008; Frogs Are Cool, 2011; Kramer, 2007). A second indicator comes from the numerous dissection alternatives now available, including computerized virtual dissections, anatomical models, films, websites, and plastinated specimens, all of which implicitly support choice (Jukes \& Chiuia, 2003; Smith \& Smith, 2004). These developments suggest choice must exist, at some level, in at least some of today's science classes.

I began to wonder, however, how consistently choice is being offered when I investigated student responses to dissection and encountered a narrative of students "going along" with the practice, even though they did not feel right about it (see for example Balcombe, 1997; Barr \& Herzog, 2000; Solot \& Arluke, 1997). This led me to question whether teachers are offering choice to students and whether that choice is being presented in a way that allows students to freely choose whether or not to dissect, without negative consequences. Aware that many teachers regard traditional dissection as the "best" way to learn and that dissection continues today as much as (if not more than) it did 50 years ago (Hart, Wood, \& Hart, 2008), I wondered how its privileged position connected to student choice.

This study examined teachers' practices, and former students' experiences, regarding choice in dissection. Drawn from a larger doctoral study (Oakley, 2011), this paper outlines quantitative and qualitative responses of former students $(n=311)$ and teachers $(n=153)$ in Ontario, Canada regarding (a) whether students are being explicitly offered a choice between participating in a dissection and using an alternative, and (b) the impressions students and teachers hold toward choice-in-dissection policies.

I approached the research from a standpoint of critical pedagogy, understood as teaching and learning practices aligned with developing students' critical consciousness (Freire, 1970; Giroux, 2001; McLaren, 1998). Recognizing that education is never politically neutral and always communicating particular ideologies that may re-entrench (or challenge) existing systems of inequality and power relations, critical pedagogy allows for a nuanced exploration of classroom dynamics while ensuring attention is given to political and axiological positions that stand outside of authoritative curricular norms. Schools are places in which political visions are constructed but they are also arenas of conflicting ideologies, and the controversies associated with dissection and choice showcase this struggle. Many teachers consider dissection an important and engaging hands-on activity (see Oakley, in press) but there are ethical questions about the practice that require critical consideration, such as whether it remains justified when there are other ways students can learn. In selecting this lens I sought a starting point that assumed that multiple possibilities for student learning exist and should be honoured, for the sake of students, animals, and progressive science pedagogy.

\section{Research Context and Design}

The research was conducted over a six-month period in 2010 in Ontario, Canada. In Ontario, the Grade 10 science and Grade 11 biology curricula state that 
students are to conduct a physical dissection or a computer-simulated dissection to achieve designated learning outcomes (Ontario Ministry of Education, 2008a, 2008 b). Based on this wording there is implied choice in the curricula, but the wording can be interpreted as meaning the choice is for teachers to make, for students to make, or for both to make. In light of this ambiguity, I sought to gain insight into how Ontario curricula are being enacted and experienced.

Two sample populations participated in this study. The "student" sample $(n=311)$ was comprised of former high school students: individuals aged 18-30, who had completed some or all of their high school science and biology classes in Ontario, and who were asked to reflect back on their schooling experiences in relation to dissection and choice. The teacher sample $(n=153)$ was comprised of science and biology teachers who were teaching, or had previously taught, high school science or biology in Ontario. The two samples populations are separate and distinct groups-i.e., the student participants were not necessarily in the classrooms of the teacher participants - and as such, the results from the two groups do not speak to a shared experience. However, given that all participants reported on their experiences in Ontario high school science and/or biology classes, a picture emerges of some of the practices and perspectives within this geographic region. The findings cannot be generalized to other regions, though, given that curricular requirements differ by province and country (and some countries do not practice dissection at all).

The data for this study was collected in quantitative and qualitative forms. The quantitative data was collected through two online surveys: one created for students (advertised via communications bulletins in Ontario universities, email advertisements, and word of mouth), and one created for teachers (advertised through the Science Teachers' Association of Ontario's newsletter and invitational emails to school boards and teachers in the province) (see Oakley, 2011 for copies of the surveys). As a small incentive to participate in the research, student participants could enter their email address in a draw to win an iPod Touch, while teacher participants could enter their email address in a draw to win a $\$ 100.00$ gift certificate from a national bookstore.

Both surveys began with qualifying questions to ensure participants formed part of the targeted demographics, then proceeded to ask participants to share their perspectives and experiences with animal dissection, objection to dissection (if applicable), and choice in the classroom. The survey questions were primarily in closed-ended formats, using checklists, "yes" or "no" (or other) answers, and five-point Likert scales that asked participants to rate whether they strongly agreed, agreed, neither agreed nor disagreed, disagreed, or strongly disagreed with a series of a priori statements. The student survey included 25 questions in total, 23 of which were in closed-ended formats, while the teacher survey included 30 questions in total, 26 of which were closed-ended. Open-ended data on both surveys was collected via questions that asked participants to share their in-class experiences in relation to the topic, as well as multiple comments fields throughout the surveys that enabled respondents to elaborate upon their answers. The statistics reported in this paper (see Tables 1 and 2) were analyzed by calculating percentages and frequencies of responses from select closed-ended survey questions. 
Both surveys were open for two months, during which time 311 responses from the student population and 153 responses from the teacher population were collected. In both groups there was a significant gender skew: $80 \%$ of student survey respondents (249 of 311 ) were female, while $64 \%$ of teacher respondents (98 of 153) were female. This gender skew highlights the possibility that the research topic may have been more interesting to women than men, perhaps deriving from the fact that females are more likely than males to object to dissection (Almy, Goldsmith, \& Patronek, 2001; Capaldo, 2004). It is likely that this gender skew influences the research findings and presents a caveat in their interpretation. At minimum, the fact that more females participated in the study than males underscores the relevance of considering the research from a gendered perspective, both in interpreting the statistical results and ascertaining who is wanting and/or willing to share their perspectives and experiences in the first place.

To complement the quantitative data, qualitative data was collected through interviews with select individuals from the two research samples. The interviews were facilitated by a question at the end of the surveys that asked participants if they would be willing to participate in a follow-up interview. From the pool of willing participants (102 individuals from the student sample and 64 from the teacher sample), I selected individuals to interview based on variety in their responses given pertaining to dissection, objection, and choice. The goal of the interviews was to further investigate individuals' experiences and perspectives. Eight interviews were conducted from the student sample ( 5 female, 3 male) and nine from the teacher sample (4 female, 5 male).

The interviews were conducted by telephone, using a semi-structured interview guide. Participants were asked to share their experiences regarding choice in the classroom, including whether and how it was offered, and how they felt about choice-in-dissection policies. All interviews were transcribed and coded using line-by-line content analysis techniques to determine emergent themes in relation to choice. These themes were then categorized in conjunction with the quantitative findings from the student and teacher surveys. This paper shares select quantitative and qualitative results from the combined survey and interview data.

\section{Findings}

Dissection was found to be a common practice, according to students and teachers, but it was also one marked by student objection and varied opinions on the necessity of offering students choice. Tables 1 and 2 outline a snapshot of statistics emerging from the surveys, providing a picture of some practices and perspectives pertaining to dissection, objection to dissection, and choice among the participating students and teachers. For further detail on the statistical findings of this research, see Oakley (2011).

The statistics suggest teachers valued dissection considerably more than students. This was evidenced by more than half of teachers (but less than a quarter of students) agreeing that all students should experience a real animal dissection. There was also a considerable difference between the two groups' reported experiences with classroom discussions on the ethics of dissection: only $28.9 \%$ of the student sample reported that their teacher held a discussion on the 
ethics of dissection, whereas $86.3 \%$ of teachers reported conducting such a discussion as part of their practice.

The data also revealed higher numbers of student objectors than teachers estimated. Among the teachers who offered dissection (144 of 153 teachers), $86.3 \%$ estimated objection rates to be between $1-5 \%$ percent in a typical classroom. Among the student sample a different trend emerged: $24 \%$ of the students who had been offered dissection reported that they harboured objections to it. However, harbouring objections to dissection did not necessarily translate into students voicing their opinions to their teachers: those who reported having objections were asked the follow-up question, "Did you inform your teacher that you did not wish to dissect?" and here only 54 of the 71 students (76\%) said "Yes." Hence, nearly a quarter of students who had objections did not speak about them.

\begin{tabular}{|c|c|}
\hline $\begin{array}{l}\text { Dissection, Objection, and Student Choice: } \\
\text { Student Survey }\end{array}$ & $\begin{array}{l}\text { Dissection, Objection, and Student Choice: Teacher } \\
\text { Survey }\end{array}$ \\
\hline Percentage of students who: & Percentage of teachers who: \\
\hline $\begin{array}{l}\text {-reported being offered dissection in } \\
\text { secondary school science classes: } 94.8 \%\end{array}$ & $\begin{array}{l}\text {-reported using dissection as an instructional } \\
\text { technique in secondary school science classes: } \\
94.1 \%\end{array}$ \\
\hline $\begin{array}{l}\text {-agreed or strongly agreed that all students } \\
\text { should experience a real animal dissection: } \\
23.2 \%\end{array}$ & $\begin{array}{l}\text {-agreed or strongly agreed that all students } \\
\text { should experience a real dissection: } 57 \%\end{array}$ \\
\hline $\begin{array}{l}\text {-reported that their teacher held a } \\
\text { classroom discussion on the ethics of } \\
\text { dissection: } 28.9 \%\end{array}$ & $\begin{array}{l}\text {-reported conducting classroom discussions } \\
\text { with students on the ethics of dissection: } \\
86.3 \%\end{array}$ \\
\hline $\begin{array}{l}\text {-reported harbouring objections to } \\
\text { dissection: } 24 \%\end{array}$ & $\begin{array}{l}\text {-estimated objection rates to be between } 1-5 \% \\
\text { in a typical class: } 86.3 \%\end{array}$ \\
\hline $\begin{array}{l}\text {-reported that their teachers gave them a } \\
\text { choice to opt out of dissection: } 60.8 \%\end{array}$ & $\begin{array}{l}\text {-reported that they verbally offer students a } \\
\text { choice to opt out of dissection: } 73.7 \%\end{array}$ \\
\hline $\begin{array}{l}\text {-agreed or strongly agreed that student } \\
\text { choice policies are needed in schools: } \\
86.7 \%\end{array}$ & $\begin{array}{l}\text {-reported that student choice policies should } \\
\text { be implemented in schools: } 47.5 \%\end{array}$ \\
\hline
\end{tabular}

Tables 1 and 2: Student and teacher survey results

More than half of the students $(60.8 \%)$ reported being given the choice to opt out of dissection, and a higher percentage of the teachers $(73.7 \%)$ indicated they offered choice. Teachers were, however, less likely than students to support the implementation of choice policies, which were defined in this study as "a written and openly declared policy that guarantees the right of students to refuse to participate in classroom activities and demonstrations that they find objectionable on the basis of personal, moral, ethical, or religious convictions, and ensures they have access without penalty to alternative learning methods, models, and 
approaches" (cf. Cunningham, 2000). Whereas 86.7\% of students agreed or strongly agreed that schools should have policies to protect students' right to choose, only $47.5 \%$ of teachers supported their implementation.

\section{Open-ended survey and interview data analysis}

The data emerging from the open-ended survey responses and interviews provided a more nuanced understanding of participants' experiences and perspectives. The following sections highlight participants' voices, speaking to themes of choice and choice policies.

On Choice in the Classroom. The qualitative data identified that the ways teachers offer choice can differ dramatically: what counts as choice is not consistent from one classroom to the next. While the quantitative data revealed that $73.7 \%$ of teachers said they offer students choice (Table 2), five clear subthemes arising from this study elucidated how choice was offered. The top five themes from the qualitative data were: (a) the "choice" or "alternative" some students were offered was to observe other students dissecting; (b) some teachers offer choice conditionally; (c) some teachers offer choice freely and provide an alternative for students to use; (d) some teachers do not offer choice at all; and (e) some teachers connect choice to grades.

The most commonly discussed theme in the narrative data was that the "choice" students were offered involved pairing with another student, or group of students, to watch them dissect. One student wrote of her classroom experience: "There was not really an alternative [offered] ... if we did not want to dissect then we could join a group and just watch. But there was no alternatives like a CD." Another noted that: "If we didn't want to dissect the animal we had to watch our other two group members do the project and instruct them what they were supposed to do." Similarly, several teachers indicated that the "alternative" they offered students was to observe a dissection without hands-on participation. One teacher outlined her classroom process of organizing dissections:

They [the students] usually work in groups of three ... I always say, "Is there anybody here who is really excited about dissecting?" and they'll put up their hands. And then I'll say, "Is there anybody here who is really nervous about it?"- and I'll say, "Okay, look at the people who just put up their hands. Pair up with them," and separate them out that way. And what normally happens is I will have a few students that are like, "Oh, Mrs. [name], I don't know if I can do this, it's kind of gross, or I really don't believe in this." And I always have a discussion with them before we start the dissection, about how wonderful it is for them to have the opportunity to work on an animal, and how special that is, and how they should really respect the fact that this animal's life was given up for them to work on it. ... I do tell students that they will have opportunity to voice their concerns to me, but I am pretty explicit-I do say, it is mandatory to take part in the dissection. It is not mandatory to pick up a pair of scissors and a scalpel and do any of the sectioning yourself, but it is mandatory to be part of a group. 
The second most commonly cited theme was that choice was offered to students conditionally. Some students and teachers explained that dissecting and using an alternative were not considered equal options in the classroom, and that students needed to provide justifiable reasons for not wanting to dissect. One student wrote: "We were told we didn't have to [dissect], but only for religious reasons or if your family were vegetarians or something... Not wanting to, or being squeamish wasn't an excuse." Another wrote that in his class, opting out of a dissection was only allowed if a student felt ill:

I do remember something about, like, if you're not comfortable, or if you feel sick, you don't have to participate or you can leave. But it was definitely not around spiritual or personal beliefs. It was more around actually physically getting sick.

Mirroring the student data, some teachers explained that students must provide a justifiable reason for not wanting to dissect. "I tell kids that if they have ethical, moral, religious, or other reasons they believe would prevent them from participating to come talk to me. We've always worked out some sort of compromise (e.g., being a hands-off observer)," one teacher wrote. Another outlined his process of asking students to gather information to defend their position if they do not want to dissect:

I'm always encouraging the kids ... to question, to be sceptical as a good scientist should be, and to always ask questions and be informed. ... I tell them, "If you have concerns, voice them. Ask questions. Be inclusive. Your opinion is valid and important, and you need answers." ... And often, if they have a belief that's very strong and opposite from what information I've given them [about the value of dissection], I tell them, "Fantastic. Go and find me some reliable information to back up what you're saying, and show it to me and I'll gladly read it and we can talk about it."... And on occasion I've had kids do that, and then it gives another opportunity to show them how sources may not be reliable, or they are reliable; are they applicable, and it keeps on going from there.

The third scenario outlined by students and teachers was that choice was clearly offered, without negative consequences, and an alternative was made available. One student wrote: "If people did not feel like participating my teachers were always accommodating. .. if it was a conflict of interest [to dissect] classmates were given models and visuals to aid in their learning process." Similarly, some teachers indicated that offering choice was an important part of their pedagogy. One teacher who offered choice proactively explained that she gives the students in her class several options:

Students are allowed to opt out completely by not being in the room and being in the library on a computer, where they do virtual dissections or explain their dilemma through a thoughtful persuasive essay, or they may choose to observe others completing the dissection. They have complete choice of their level of involvement. 
The fourth most commonly cited theme was that choice was not offered at all. With $39.2 \%$ of students reporting they were not offered choice in the classroom and $26.3 \%$ of teachers saying they do not offer choice (Tables 1 and 2), several participants referenced this theme. One student explained:

There wasn't an option. I went and asked my teacher. The thing is, where I was, at least at the time anyway, it was up to the teacher whether or not you could opt out. My sister went to the same school, and she had a different teacher, and they let people opt out, but I had the teacher that I had, and I went and asked and they said, "No, you have to participate." So everybody in our class had to do it.

Among the teachers who discussed their reasons for not giving choice, some expressed that they viewed conventional dissection as part of the curriculum and therefore saw no reason to offer choice. "If they don't want to dissect, take another course," one teacher wrote, while another opined that giving choice is a poor idea because "if you are taking a senior biology class, you should have to use dissection since it will be done at most universities. It is part of science research." Some added that the choice outlined in the curriculum (that students will either conduct a physical or virtual dissection) was their choice to make as teachers. "Due to a teacher's loco parentis I believe it is OUR choice and the Ministry of Education to make the decisions for the science curriculum," one teacher commented.

Finally, complications around the interpretation of choice emerged from narrative data revealing that some teachers connected marks to student choice. Some students commented that their participation in a dissection was implicitly or explicitly tied to their grades: "[My teacher] told me I would lose $15 \%$ of my mark for not participating" one student indicated. Another noted that:

I was told that if I took the alternative I would be marked harder and that she [the teacher] would purposely make it a harder assignment because she wanted us to do the actual dissection.... [she] made it known that it would be harder for me to receive a good grade if I chose the alternative.

Two teachers in the study also indicated that they marked students differently based on whether they participated or used an alternative. One wrote: "I use the dissection as their FCA [final course assignment], therefore if they decide not to do it, then they only lose $10 \%$ of their overall mark." Another indicated that the alternative he offered was a particularly difficult assignment, and one that "most [students] really don't want to do. I don't make it a pleasant assignment, very specifically, especially at the senior levels."

On Student Choice Policies. The patterns in the qualitative data pertaining to student choice policies largely reflected the quantitative data, in which most students $(86.7 \%)$ saw a place for choice policies in the classroom but slightly less than half of the teachers $(47.5 \%)$ were in favour of their implementation (Tables 1 and 2). The majority of the student qualitative data outlined students' reasoning for wanting choice policies, often connected to their classroom experiences and 
the reality that not every student is given choice unconditionally and some are not given choice at all. The teacher data set was much more mixed, with many teachers explaining that they saw choice policies as unnecessary classroom legislation.

Several students commented that choice should be understood as a student's right, motivated by ethical or other reasons. "There are so many different variables that might affect a student's personal reasons [for not wanting to dissect] and whether they feel comfortable in the classroom," one student explained, adding that: "If people just find it gross, or if they find it unethical, then they should have the right to abstain from it." Others suggested choice policies were important to ensure that students who choose not to dissect are not punished for their decision: "It is not right to penalize them for them for not wishing to take part in this cruel practice (killing animals for dissection use). Now that it is 2010 there should be alternatives [made available]."

Others framed choice policies as a means of ensuring that it is not uncomfortable or prohibitive for students to opt out of dissection. One student commented that since classroom dynamics differ considerably, choice policies are especially important in classrooms where students may find it difficult to broach the topic with their teacher:

I think it [student choice] should be a legal policy, because the classroom-to-classroom basis can change. If you have a really intimidating teacher, then you're not going to approach them about it, or you're less likely to approach them about it, so making it a legal policy ensures that students won't be affected by approaching their teacher.

Not all students saw value in choice policies, however. Among those who commented on their reasons for believing choice policies should not be implemented in the classroom, responses ranged from believing teachers will give options (sometimes based on personal experiences) to the opinion that choice policies should be "common sense" and are not necessarily "legal" in nature. One student explained:

I think it shouldn't really be a legal thing. I think it should be made aware in any situation that like, the student does not have to do anything they don't want to, and that should be basically a given. It shouldn't have to be a legal thing, but it should just be common sense.

Less than half of the teachers reported that they saw value in adopting student choice policies, but among those who did, opinions were expressed that choice policies could help teachers open up a class conversation about why dissection is a controversial practice. One teacher wrote:

Students need to be encouraged to be critical thinkers who question things - they should not blindly accept any idea presented to them. A student choice policy encourages this skepticism and challenging of norms, which is the basis of scientific progress. Hand in hand with this 
comes the skill of logically justifying beliefs, which is what students are encouraged to do when they question and challenge the status quo.

Other teachers indicated that choice policies equate to respecting students' reasons for not wanting to participate in a dissection. "Students should never be forced to do something they find morally, ethically, religiously or personally objectionable," one teacher wrote in support of choice policies, adding that: "Discussion [of choice policies] should allow a learning opportunity about other points of view." Another teacher indicated that choice policies are relevant because student learning can be achieved in various ways, so there is no need to push a student to dissect if she or he is opposed to it:

I find nothing problematic about the policy. You can bring a horse to water ... If the student doesn't want to engage, then so be it. I am always open to what is win/win and a student genuinely interested in learning, there has never been a problem finding a workable compromise.

Of the teachers who did not agree with choice policies, some wrote the policies are unnecessary because students who object will speak their minds. "Quite frankly, the students who have objections are generally comfortable in speaking out," one teacher wrote, while others suggested that students should undergo the process of speaking out against a curricular practice they are opposed to, as a goal of education is to develop critical thinkers who can express their perspectives. Some argued that policies usurp a teacher's responsibility to discuss the controversies associated with dissection and could in fact negate a classroom discussion about ethics and choice. "The whole concept of making it into a policy, to me, just eliminates my role as a teacher. Like, I'm not allowed then to give the students opportunities to even present their agreement or disagreement?" one teacher asked.

Another theme emerging from the teacher data was concern that choice policies would lead to too many students objecting without making an informed decision, as they might latch on to their first reaction-e.g., that they find dissection "gross" - and opt out because of it. One teacher wrote that "giving them options is not always productive to their education or their development as scientists, good citizens, environmental stewards. They may choose not to participate in certain activities which are actually going to benefit them in ways they don't understand." Another characterized choice policies as:

...a double-edged sword. Students' freedom of conscience must be respected, but, there are a LOT of students who don't WANT to do it but not for a defensible reason. An open "student choice" policy would be disastrous since it would essentially allow students the lazy way out. Life is not always easy and if students do not have the experience of facing up to challenges they're going to leave high school unprepared for adult relationships and decisions.

The diverse perspectives surrounding choice policies demonstrate that students and teachers had different viewpoints on the issue of choice, and that 
within the teacher group in particular, there was no consensus on whether choice policies are relevant or necessary.

\section{Discussion}

A pressing concern arising from this study is that not all students are explicitly offered choice in dissection, some are offered it only conditionally, and some are denied it altogether. These varied realities point to a need for standardized practices via choice-in-dissection policies. Choice policies are progressive policies that ensure that students who do not want to dissect are treated consistently and fairly, and that teachers are prepared to respond to those who object (Duncan, 2008; Kramer, 2007). A primary recommendation emerging from this study is thus for teachers to adopt formalized choice policies in their classrooms.

A formalized choice policy includes three components: (a) written and verbal components: students are informed verbally (e.g., through class discussion) and in writing (e.g., via a passage included in a course syllabus) that they do not have to dissect, that there is no penalty for choosing alternatives, and that a comparable alternative is available to them; (b) no demand on students to obtain parental consent to substantiate their choice; and (c) no expectation on teachers to dissect, as the choice applies to both students and teachers (Balcombe, 2001; Duncan, 2008). In other words, choice must be communicated clearly to students (and teachers) and offered freely without conditions or negative consequences; further, a viable alternative must be made available. This "alternative" should not be for students to observe others dissecting, but for them to use an alternate way of learning-outside of the classroom environment, if they so choose- to achieve the designated learning outcomes.

Although choice policies can mean extra work for teachers in terms of selecting and procuring alternatives, there are multiple benefits to their adoption. One obvious benefit is that choice policies demonstrate respect for students' varied ethical, cultural, and religious backgrounds, ensuring their perspectives are honoured and not silenced in the classroom. As some teachers in this study noted, choice policies can provide an opportunity to open up class conversation about the controversies associated with dissection and the reasons why some people choose not to dissect. In doing so, they can offer a "teachable moment" to expose students to some of the proven alternate ways of learning about animal anatomy and physiology without relying on killing animals. As numerous studies have shown, students can learn equally, and sometimes better, from performing a virtual dissection than from conducting a real one (Balcombe, 2003; Kopec, 2002; Lalley, Piotrowski, Battaglia, Brophy, \& Chugh, 2010; Maloney, 2005; Montgomery, 2008; Youngblut, 2001). These studies suggest that a common rationale among some teachers - that dissection is the "best" way students can learn-is unfounded (Oakley, in press).

Schools are also likely to realize cost benefits in using computerized alternatives to dissection, given that alternatives can be re-used year after year (PCRM, 2004). In addition, there are noteworthy environmental benefits associated with using alternatives; for example, the fact that some animals (e.g., frogs) continue to be wild-caught means that dissection can result in ecosystem disruption and stress on vulnerable amphibian populations (Rosenberger, 1998). 
Further, as many dissected animal cadavers are still preserved in formalin, there are associated health concerns for those who work in biological supply companies and those who dissect animals (Jukes \& Chiuia, 2003). The potential cost benefits of using alternatives, combined with environmental and health concerns, and the ethical and pedagogical questions of why schools continue to dissect when there are other ways students can learn, form cogent arguments for reducing or replacing animal dissection as well as offering students choice (Oakley, 2009).

Choice policies are consistent with progressive interpretations of the Ontario curriculum. Currently, the curriculum indicates that students are to perform either a physical dissection or a computer-simulated dissection; a literal interpretation of this wording would suggest that choice should already be a regular pedagogical offering. The Grades 10 and 11 Ontario curricular documents further suggest that "students should be encouraged to use ICT [information and communications technology] to support and communicate their learning" and that "technology ... makes it possible to use simulations - for instance, when field studies on a particular topic are not feasible or dissections are not acceptable" (Ontario Ministry of Education, 2008a, p. 40; Ontario Ministry of Education, 2008b, p. 42). Given the multi-faceted concerns associated with dissection, a one-style-fits-all practice is not in keeping with the curricular focus on using ICT and offering students choice. Rather, it is a replication of traditional modes of scientific inquiry and models of teaching that see the teacher as the ultimate authority figure who decides how students will learn.

Choice policies model the reality that not all students respond to dissection in the same way. They also communicate to student objectors that their values have relevance in the scientific world and that a commitment to avoiding harmful animal use is laudable. As Kramer (2007) writes, choice policies "open up the door to a new generation of scientists who, from their earliest learning, approach science as an intrinsically humane process that neither wastes nor abuses animal life" (pp. 285-286). This approach is also in keeping with commitments from the international scientific community toward the "Three Rs" of replacing, reducing, and refining harmful animal use in scientific and educational contexts (Russell \& Burch, 1959; Hart et al., 2008; King, 2004; Smith \& Smith, 2004). While dissection in Kindergarten-Grade 12 schools is largely unregulated in North American contexts - for example, schools in Canada are not required to maintain any records on animal use (CCAC, 2006) - the "Three Rs" guideline is more rigorously applied in post-secondary educational contexts (Hart et al., 2008). Further, in countries outside of North America, an application of the Three Rs ideology has resulted in the discontinuation of classroom-based dissections, which are no longer practiced in primary and secondary schools in The Netherlands, Switzerland, Argentina, Slovak Republic, and Israel, and is rare in schools in Sweden, Germany, and England (Balcombe, 2001; Waltzman, 1999).

From a critical pedagogy standpoint, choice policies support a classroom in which the power of the teacher is mitigated in favour of an environment where the teacher and students co-construct meaning together. As Kincheloe (2005) writes, "any time teachers develop a pedagogy, they are concurrently constructing a political vision" (p. 9), which speaks to the nature of education as intimately bound with politics and power. In this research it was evident that 
some teachers wield power by deciding how the dissection curriculum will be enacted, but choice policies mollify these power dynamics by respecting students' perspectives and encouraging them to come to a critical consciousness by making choices based on their value systems. With the teacher acting as facilitator, students can engage with the various political positions that surround dissection and practice scepticism by asking if dissection is the only, or best way, for them to learn.

Ultimately, choice policies are a middle-of-the-road approach. They do not impede teachers' freedom to continue offering dissection, but ensure that students with ethical, cultural, or religious objections are given alternate and equivalent ways to achieve curricular goals. The findings of this research point to the importance of choice policies, given students' uneven classroom experiences and teachers' varied practices. Without a standardized approach in place, it is likely that choice will continue be offered haphazardly, with some conscientious teachers incorporating it into their teaching while others eschew it or offer it only conditionally. The need for choice policies is evident, as the policies equate to respecting students as moral agents and treating them fairly and consistently. After all, why should some students have the right to refuse dissection, while others do not?

\section{Acknowledgments}

This research was supported by a grant from the Social Sciences and Humanities Research Council of Canada.

\section{References}

Almy, J., Goldsmith, M., \& Patronek, G. (2001). Dissection in Massachusetts classrooms: Correlation of gender, teacher attitudes, and conscientious objection. (Report). West Barnstable, MA: Cape Wildlife Center.

American Anti-Vivisection Society (AAVS). (2011). Vermont enacts student choice legislation! [Press release]. Retrieved from http://www.aavs.org/site/c.bkLTKfOSLhK6E/b.6453015/k.FCBD/Vermont Enacts Student Choice Legislation.htm

Balcombe, J. (1997). Student/teacher conflict regarding animal dissection. American Biology Teacher, 59(1), 22-25.

Balcombe, (2000). The use of animals in higher education: Problems, alternatives, and recommendations. Washington, DC: The Humane Society Press.

Balcombe, J. (2001). Dissection: The scientific case for alternatives. Journal of Applied Animal Welfare Science, 4, 118-126.

Balcombe, J. (2003). Assessment of alternatives in education. In N. Jukes \& M. Chiuia (Eds.), From guinea pig to computer mouse: Alternative methods for a progressive, humane education ( $2^{\text {nd }}$ ed.) (pp. 40-53). Leicester, England: InterNICHE.

Barr, G. \& Herzog, H. (2000). Fetal pig: The high school dissection experience. Society \& Animals: Journal of Human-Animal Studies, 8(1), 53-69.

Canadian Council on Animal Care (CCAC). (2006). Manual for community representatives. Ottawa, ON: Canadian Council on Animal Care.

Canadian Council on Animal Care (CCAC). (2010). Teaching and the Three Rs. Retrieved from http://www.ccac.ca/en/alternatives/teaching enseignement.html

Capaldo, T. (2004). The psychological effects on students of using animals in ways that they see as ethically, morally or religiously wrong. Alternatives to Laboratory Animals, 32(1), 525-531.

Cunningham, P. (2000). Animals in psychology education and student choice. Society \& Animals: 
Journal of Human-Animal Studies, 8(2), 191-212.

Duncan, A. (2008). To dissect or not: Student choice-in-dissection laws ensure the freedom to choose. Journal of Law and Education, 37(2), 283-289.

Freire, P. (1970). Pedagogy of the oppressed (M. Bergman Ramos, Trans.). New York: Continuum. Frogs Are Cool. (2011). Campaigns. Retrieved from www.frogsarecool.com/campaigns.htm

Giroux, H. (2001). Theory and resistance in education: Towards a pedagogy for the opposition. Westport CT: Begin \& Garvey.

Hart, L. A., Wood, M. W., \& Hart, B. L. (2008). Why dissection? Animal use in education. Westport, CT: Greenwood Press.

Jukes, N. \& Chiuia, M. (2003). From guinea pig to computer mouse: Alternative methods for a progressive, humane education ( $2^{\text {nd }}$ ed.). Leicester, England: InterNICHE.

Kincheloe, J. (2005). Critical pedagogy primer. New York: Peter Lang Publishing.

King, L. A. (2004). Ethics and welfare of animals used in education: An overview. Animal Welfare, $13, \mathrm{~S} 221-224$.

Kopec, R. H. (2002). Virtual, on-line, frog dissection vs. conventional laboratory dissection: A comparison of student achievement and teacher perceptions among honors, general ability, and foundations-level high school biology classes (Doctoral dissertation). Retrieved from ProQuest Dissertations and Theses Database (UMI No. 3040985).

Kramer, M. G. (2007). Humane education, dissection, and the law. Animal Law, 13, 281-298.

Lalley, J. P., Piotrowski, P. S., Battaglia, B., Brophy, K., \& Chugh, K. (2010). A comparison of VFrog $($ to physical frog dissection. International Journal of Environmental and Science Education, 5(2), 189-200.

Maloney, R. (2005). Exploring virtual fetal pig dissection as a learning tool for female high school biology students. Educational Research and Evaluation, 11(6), 591-603.

Marr, R. K. (2001). Dissection: Where and when is it appropriate in the teaching laboratory? Journal of Applied Animal Welfare Science, 4(2), 139-141.

McLaren, P. (1998). Life in schools: An introduction to critical pedagogy in the foundations of education. New York: Longman.

Montgomery, L. (2008). A comparison of the effectiveness of virtual and traditional dissection on learning frog anatomy in high school (Doctoral dissertation). Retrieved from ProQuest Dissertations and Theses Database (UMI No. 3287762).

Nobis, N. (2002). Response to Balcombe's commentators: Animal dissection and evidence-based life-science and health-professions education. Journal of Applied Animal Welfare Science, $5(2), 157-161$.

Oakley, J. (2009). Under the knife: Animal dissection as a contested school science activity. Journal for Activist Science and Technology Education, 1(2), 59-67.

Oakley, J. (2011). Cutting edge controversy: The politics of animal dissection and responses to student objection. Unpublished doctoral dissertation. Lakehead University, Thunder Bay, ON.

Oakley, J. (in press). Science teachers and the dissection debate: Perspectives on animal dissection and alternatives. International Journal of Environmental and Science Education.

Ontario Ministry of Education. (2008a). The Ontario curriculum, Grades 9 and 10: Science. Ontario: Ontario Ministry of Education.

Ontario Ministry of Education. (2008b). The Ontario curriculum, Grades 11 and 12: Science. Ontario: Ontario Ministry of Education.

Physicians Committee for Responsible Medicine (PCRM). (2004). Cost analysis of dissection versus nonanimal teaching methods. (Fact sheet). Washington, DC: PCRM.

Rosenberger, J. (1998, July/August). Harvest of shame: Dissection's deadly toll hits frogs hardest. E Magazine, 9(4), 26-27.

Russell, W. M. S. \& Burch, R. L. (1959). The principles of humane experimental technique. London: Methuen. Retrieved from http://altweb.jhsph.edu/pubs/books/humane exp/het-toc

Smith, A. J. \& Smith, K. (2004). Guidelines for humane education: Alternatives to the use of animals in teaching and training. Alternatives to Laboratory Animals, 32(1), 29-39.

Solot, D. \& Arluke, A. (1997). Learning the scientist's role: Animal dissection in middle school. Journal of Contemporary Ethnography, 26(1), 28-54. 
Waltzman, H. (1999). Dissection banned in Israeli schools. Nature, 402(23), 845.

Youngblut, C. (2001). Use of multimedia technology to provide solutions to existing curriculum problems: Virtual frog dissection (Doctoral dissertation). Retrieved from ProQuest Dissertations and Theses Database (UMI No. 3008579).

Jan Oakley, PhD is a contract lecturer in the Faculty of Education and Department of Women's Studies at Lakehead University in Thunder Bay, Canada. Email joakley@lakeheadu.ca 